\title{
PENERAPAN VALUE ENGINEERING DALAM PEMILIHAN JENIS BEKISTING KOLOM BETON PADA KONSTRUKSI GEDUNG BERTINGKAT
}

\author{
Steven $^{1}$ dan Jane Sekarsari Tamtana ${ }^{2}$ \\ ${ }^{1}$ Program Studi Sarjana Teknik Sipil, Universitas Tarumanagara, Jl. Letjen S. Parman No.1 Jakarta \\ steven.325160114@stu.untar.ac.id \\ ${ }^{2}$ Jurusan Teknik Sipil, Universitas Trisakti, Jl. Kyai Tapa No.1 Jakarta \\ tamtana.js@gmail.com
}

Masuk: 15-01-2020, revisi: 11-02-2020, diterima untuk diterbitkan: 26-02-2020

\begin{abstract}
Value engineering is a sistematic and structured approach to increase the value of a project, product, and process. Value engineering helps in achieving an optimum balance between function, performance, quality, safety, and cost, so that the maximum value for a project can be achieved. In its application, value engineering can be used to analyze a project as a whole or to analyze specific works in a project, one of them is the formwork installation. Formwork is a temporary structure used to support and protect fresh concrete until it could support itself. Based on the function of the formwork itself, formwork becomes an inseparable part of a building's structural component making process such as beam, colum, slab, etc. In this study, an analysis to determine the best type of formwork for the construction of a building's columns using value engineering analysis was done. Based on the results of this study, it can be concluded that aluminium formwork is the best alternative for column formwork and quality is the most influential criteria on the installation of column formwork.
\end{abstract}

Keywords: value engineering; formwork; column.

\begin{abstract}
ABSTRAK
Value engineering adalah sebuah pendekatan yang sistematis dan terstruktur untuk meningkatkan nilai suatu proyek, produk, dan proses. Value engineering membantu dalam mencapai keseimbangan yang optimum antara fungsi, performa, kualitas, keamanan, dan biaya, sehingga dapat dicapai nilai yang maksimum untuk suatu proyek. Dalam penerapannya, value engineering dapat digunakan untuk menganalisis suatu proyek secara keseluruhan maupun menganalisis pekerjaan-pekerjaan dalam suatu proyek secara spesifik, salah satunya adalah pekerjaan pemasangan bekisting. Bekisting adalah suatu struktur sementara dengan tujuan untuk mendukung dan melindungi beton segar sampai beton tersebut dapat mendukung diri sendiri. Berdasarkan fungsi dari bekisting itu sendiri, maka bekisting menjadi suatu bagian yang tidak dapat dipisahkan dari proses pembuatan komponen struktur suatu gedung bertingkat seperti balok, kolom, pelat, dan struktur-struktur lainnya. Dalam penelitian ini, dilakukan analisis untuk menentukan jenis bekisting terbaik untuk digunakan dalam konstruksi kolom gedung bertingkat dengan menggunakan analisis value engineering. Berdasarkan hasil dari penelitian ini, dapat disimpulkan bahwa bekisting aluminium merupakan alternatif terbaik untuk bekisting kolom dan kriteria mutu/hasil cetakan beton merupakan kriteria yang paling berpengaruh terhadap pekerjaan pemasangan bekisting kolom.
\end{abstract}

Kata kunci: value engineering; bekisting; kolom.

\section{PENDAHULUAN}

Bahan bangunan yang paling banyak digunakan dalam konstruksi struktur utama dari suatu gedung bertingkat adalah beton. Dalam proses pengerjaan struktur bangunan dengan bahan beton pastilah tidak terlepas dari tahap pengecoran beton itu sendiri. Pada proses pengecoran beton, diperlukan suatu material yang dapat menjadi cetakan/wadah bagi beton agar nantinya bentuk serta ukuran dari struktur yang akan dibuat sesuai dengan gambar rencana bangunan tersebut. Proses pengecoran beton pastilah akan terus dilakukan mulai dari pengerjaan lantai dasar hingga lantai paling atas dari gedung tersebut, serta pada proses pengerjaannya diperlukan suatu material yang dapat menjadi cetakan/wadah bagi beton agar nantinya bentuk serta ukuran dari struktur yang akan dibuat sesuai dengan gambar rencana bangunan tersebut. Dalam proses inilah bekisting memegang peranan yang penting. 
Bekisting adalah suatu struktur sementara dengan tujuan untuk mendukung dan melindungi beton segar sampai beton tersebut dapat mendukung diri sendiri, sehingga bentuk, ukuran beton, posisi, dan letak bangunan sesuai dengan yang diinginkan (Hanna, 1998). Berdasarkan fungsi dari bekisting itu sendiri, maka bekisting menjadi suatu bagian yang tidak dapat dipisahkan dari proses pembuatan komponen struktur suatu gedung bertingkat seperti balok, kolom, pelat, dan struktur-struktur lainnya. Melihat pentingnya peranan bekisting dari awal hingga akhir dari suatu proyek konstruksi gedung bertingkat, maka perlu dilakukan serangkaian analisis agar dapat dipilih jenis bekisting yang dapat memberikan performa dan kualitas terbaik.

Terdapat beberapa penelitian terdahulu yang dilakukan untuk menentukan jenis bekisting terbaik untuk digunakan, seperti penelitian yang dilakukan oleh Pratama, dkk. (2017) untuk menentukan tipe bekisting kolom yang dapat memberikan biaya terendah serta waktu pengerjaan tercepat dengan metode analisis biaya serta analisis waktu, dan penelitian yang dilakukan oleh Nugroho (2018) untuk menentukan jenis bekisting kolom yang dapat menghasilkan biaya terendah dengan metode analisis harga satuan pekerjaan, namun masih belum ada penelitian yang dilakukan untuk menentukan jenis bekisting terbaik dengan menggunakan metode analisis value engineering.

Value engineering adalah evaluasi sistematis atas desain engineering suatu proyek untuk mendapatkan nilai yang paling tinggi bagi setiap dolar yang dikeluarkan. Selanjutnya value engineering mengkaji dan memikirkan berbagai komponen kegiatan seperti pengadaan, fabrikasi, dan konstruksi serta kegiatan-kegiatan lain dalam kaitannya antara biaya terhadap fungsinya, dengan tujuan mendapatkan penurunan biaya proyek secara keseluruhan (Fisk, 1982). Dengan menggunakan metode analisis value engineering, dapat dicapai keseimbangan yang optimum antara fungsi, performa, kualitas, keamanan, dan biaya, sehingga dapat dicapai nilai (value) yang maksimum untuk suatu proyek (Society of American Value Engineers). Oleh sebab itu, pada penelitian ini dilakukan serangkaian analisis menggunakan metode analisis value engineering dengan tujuan untuk menentukan jenis bekisting kolom terbaik yang dapat digunakan pada konstruksi kolom gedung bertingkat.

\section{METODE PENELITIAN}

\section{Pengumpulan Data}

Data-data yang dikumpulkan dalam penelitian ini diperoleh dari:

1. Wawancara dan Kuesioner

Berdasarkan hasil wawancara serta pengisian kuesioner oleh narasumber, diperoleh pendapat serta penilaian dari narasumber mengenai setiap jenis bekisting yang diteliti.

\section{Studi Pustaka}

Berdasarkan hasil studi pustaka yang dilakukan, diperoleh informasi mengenai jenis-jenis bekisting yang dapat digunakan untuk kolom yaitu plywood dilapisi film, aluminium, dan baja. Melalui studi pustaka juga diperoleh beberapa referensi mengenai metode analisis value engineering yang dilakukan pada penelitian ini.

\section{Pengolahan Data}

Penelitian ini dilakukan secara bertahap sesuai dengan tahapan dalam metode analisis value engineering. Namun ada beberapa tahap yang dihilangkan untuk menyesuaikan dengan penelitian ini, yaitu tahap implementasi dan tahap tindak lanjut. Berikut ini adalah tahap-tahap yang dilakukan dalam penelitian ini.

\section{Tahap Informasi}

Pada tahap informasi ini, dilakukan pengumpulan data-data seputar proyek yang diperlukan dalam penelitian ini berupa denah kolom, ukuran kolom, serta tinggi antar lantai bangunan. Selain itu, dilakukan pula pencarian jenisjenis bekisting yang dapat digunakan dalam konstruksi kolom beton. Hal ini bertujuan untuk memperoleh alternatif-alternatif yang diseleksi pada tahap analisis.

\section{Tahap Fungsi}

Pada tahap fungsi ini, dilakukan dua buah pekerjaan yaitu pendefinisian fungsi serta pembuatan diagram FAST (Function Analysis System Technique). Untuk melakukan pendefinisian fungsi, diperlukan dua buah kata, yaitu satu kata kerja dan satu kata benda untuk setiap fungsi dari bekisting. Setelah melakukan pendefinisian fungsi, selanjutnya adalah pembuatan diagram FAST. Pembuatan diagram FAST dimulai dengan mengajukan pertanyaan "bagaimana" fungsi dasar dilaksanakan. Pertanyaan ini dijawab oleh fungsi lain diletakkan disebelah kanan dari fungsi dasar. Seterusnya diajukan pertanyaan "bagaimana" secara terus-menerus terhadap fungsi baru yang muncul. Kemudian diajukan pertanyaan "mengapa" terhadap fungsi yang berada di paling kanan dalam pada diagram FAST. Pertanyaan "mengapa" fungsi tersebut diperlukan, akan dijawab oleh fungsi yang terletak di sebelah kiri fungsi tersebut. 


\section{Tahap Kreatif}

Pada tahap kreatif ini, dilakukan identifikasi kriteria-kriteria yang digunakan pada analisis teknik pemeringkatan, matriks perbandingan berpasangan, dan matriks keputusan. Pengidentifikasian kriteria-kriteria ini dilakukan melalui wawancara serta diskusi dengan narasumber.

\section{Tahap Analisis}

Pada tahap ini, dilakukan analisis serta evaluasi terhadap jenis-jenis bekisting kolom yang telah diperoleh dari tahap kreatif. Teknik analisis pertama yang digunakan adalah analisis keuntungan dan kerugian. Sesuai dengan namanya, pada analisis ini dilakukan identifikasi keuntungan dan kerugian dari masing-masing alternatif yang ada. Setelah dilakukan analisis keuntungan dan kerugian, selanjutnya dilakukan evaluasi dengan teknik pemeringkatan/ranking technique. Dalam penggunaan teknik pemeringkatan ini, perlu dilakukan identifikasi kriteria-kriteria yang sesuai terlebih dahulu. Kriteria yang digunakan pada teknik pemeringkatan ini didapat melalui diskusi serta wawancara dengan narasumber. Setelah didapatkan kriteria yang sesuai, masing-masing jenis bekisting diberi skor oleh narasumber berdasarkan kriteria-kriteria yang telah diidentifikasi. Rentang nilai yang dapat diberikan adalah dari 1-5. Kemudian skor dari masing-masing kriteria dijumlahkan dan dirata-ratakan. Jenis bekisting dengan nilai rata-rata tertinggi diberi peringkat 1 , begitupun seterusnya.

Berikutnya dilakukan evaluasi dengan pembuatan matriks perbandingan berpasangan. Dalam matriks perbandingan berpasangan ini, setiap kriteria yang telah diidentifikasi dibandingkan satu sama lain. Skor perbandingan terkecil adalah 0 , dan skor terbesar adalah 3. Dari hasil penilain matriks perbandingan berpasangan di atas, selanjutnya dibuat tabel yang berisi total skor serta peringkat dari masing-masing kriteria. Fase terakhir dalam tahap analisis ini adalah pembuatan matriks keputusan/decision matrix. Hasil dari matriks keputusan ini lah yang nantinya menentukan alternatif mana saja yang dianalisis lebih lanjut pada tahap pengembangan. Pada matriks keputusan ini, dilakukan perhitungan skor akhir dari masing-masing alternatif dengan cara mengalikan skor dari setiap kriteria yang dimiliki masing-masing alternatif, yang diperoleh dari analisis teknik pemeringkatan dengan skor masing-masing alternatif yang diperoleh dari matriks perbandingan berpasangan. Nantinya, hasil perkalian masing-masing kriteria yang dimiliki oleh tiap alternatif dijumlahkan untuk mendapatkan skor akhir.

\section{Tahap Pengembangan}

Pada tahap pengembangan ini, dilakukan perhitungan biaya untuk pengadaan material dan aksesoris bekisting dari masing-masing alternatif bekisting kolom yang diteliti.

6. Tahap Rekomendasi

Pada tahap ini, dipaparkan secara ringkas dan jelas mengenai hasil studi yang dilakukan dalam penelitian ini berdasarkan analisis yang telah dilakukan.

\section{HASIL DAN PEMBAHASAN}

\section{Tahap Informasi}

Pada tahap ini dikumpulkan informasi-informasi yang diperlukan dalam penelitian yaitu tinggi setiap lantai pada bangunan yang ditinjau dan denah kolom pada bangunan yang ditinjau. Selain itu juga dikumpulkan informasi mengenai jenis-jenis bekisting yang dapat digunakan dan diperoleh tiga jenis bekisting yang dianalisis pada penelitian ini yaitu plywood dilapisi film, aluminium, dan baja.

\section{Tahap Fungsi}

\section{Identifikasi Fungsi}

Pada tabel yang terletak di halaman berikutnya (Tabel 1), terdapat beberapa fungsi dari bekisting yang telah diidentifikasi dan dipaparkan dalam bentuk kata kerja dan kata benda, serta keterangan tambahan yang menandakan apakah fungsi tersebut merupakan fungsi primer atau sekunder. 
Penerapan Value Engineering dalam Pemilihan Jenis

Steven et al Bekisting Kolom Beton pada Konstruksi Gedung Bertingkat

Tabel 1. Fungsi Bekisting Kolom

\begin{tabular}{ccc}
\hline Kata Kerja & Kata Benda & Keterangan \\
\hline Memberikan & Daya Dukung & Primer \\
Mencetak & Beton & Primer \\
Menahan & Beban & Primer \\
Memberi & Bentuk & Primer \\
Mempertahankan & Dimensi & Primer \\
Menyangga & Beton & Primer \\
Memperoleh & Kolom Rencana & Primer \\
Menutup & Permukaan & Primer \\
Melindungi & Permukaan & Sekunder \\
Menjaga & Kehalusan Permukaan & Sekunder \\
Mempermudah & Pekerjaan & Sekunder \\
\hline
\end{tabular}

\section{Diagram FAST}

Diagram FAST (Function Analysis System Technique) yang telah disusun berdasarkan fungsi-fungsi dari bekisting kolom yang telah diidentifikasi di atas, ditampilkan pada gambar di halaman berikutnya (Gambar 1).

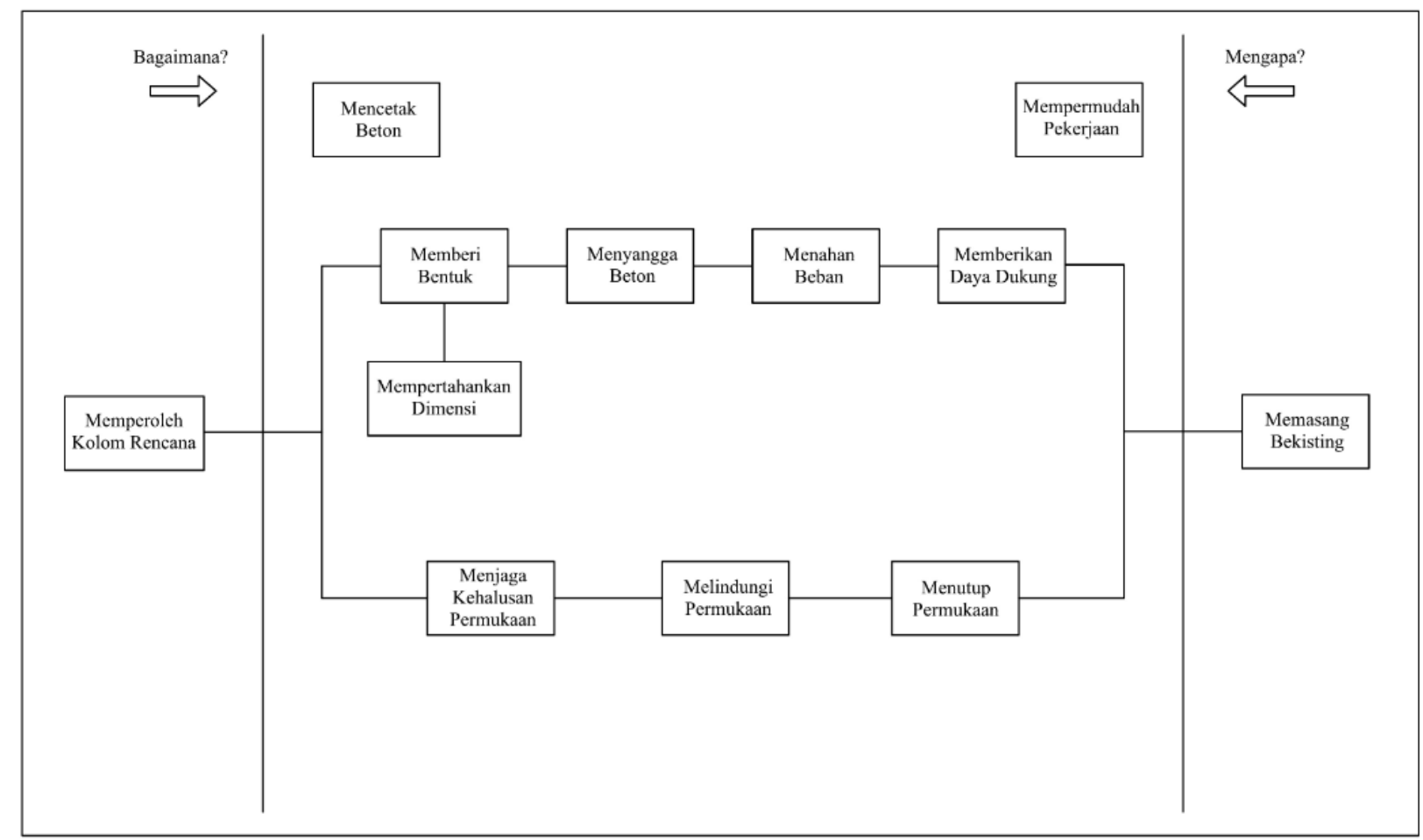

Gambar 1. Diagram FAST 


\section{Tahap Kreatif}

Pada tahap ini dilakukan identifikasi kriteria-kriteria yang diperlukan pada tahap analisis. Proses identifikasi kriteria-kriteria ini dilakukan melalui wawancara serta diskusi dengan beberapa narasumber. Kriteria-kriteria yang telah diidentifikasi adalah:

\section{Kemudahan Pengerjaan}

Kriteria kemudahan pengerjaan didefinisikan sebagai mudah atau sulitnya suatu jenis bekisting dikerjakan di lapangan secara umum.

\section{Waktu Pengerjaan}

Kriteria waktu pengerjaan didefinisikan sebagai cepat atau lambatnya suatu jenis bekisting dikerjakan di lapangan secara umum.

\section{Biaya}

Kriteria biaya didefinisikan sebagai tinggi atau rendahnya yang dikeluarkan dalam penggunaan suatu jenis bekisting. Biaya yang termasuk pada kriteria ini meliputi biaya untuk pengadaan material bekisting serta biaya untuk pengadaan aksesoris-aksesoris bekisting.

\section{Mutu/Hasil Cetakan Beton}

Kriteria mutu/hasil cetakan beton didefinisikan sebagai halus atau tidaknya permukaan kolom yang dihasilkan oleh suatu jenis bekisting, serta ada atau tidak adanya kerusakan pada kolom yang dihasilkan oleh suatu jenis bekisting.

\section{Ketersediaan Material}

Kriteria ketersediaan material didefinisikan sebagai mudah atau tidaknya dalam mendapatkan material yang diperlukan untuk suatu jenis bekisting.

\section{Durabilitas}

Kriteria durabilitas ini didefinisikan sebagai ketahanan dari material suatu jenis bekisting, apakah materialmaterialnya mudah mengalami kerusakan setelah proses pengecoran atau akibat benturan.

\section{Tahap Analisis}

\section{Analisa Keuntungan dan Kerugian}

Pada bagian ini dipaparkan mengenai keuntungan dan kerugian dari masing-masing jenis bekisting yang dapat digunakan untuk konstruksi kolom beton, yang ditampilkan pada Tabel 2 hingga Tabel 4.

Tabel 2. Keuntungan dan Kerugian Bekisting Plywood Dilapisi Film

\begin{tabular}{ll}
\hline Keuntungan & Kerugian \\
\hline Fleksibilitas tinggi & Menghasilkan limbah sisa plywood \\
Biaya yang dikeluarkan di awal lebih rendah & Jumlah penggunaan terbatas \\
$\begin{array}{l}\text { Biaya total yang dikeluarkan lebih rendah } \\
\text { dibandingkan bekisting aluminium dan baja, } \\
\text { apabila digunakan pada proyek berskala kecil }\end{array}$ & Durabilitas material rendah \\
Material ringan & $\begin{array}{l}\text { Menghasilkan permukaan kolom yang } \\
\text { kurang halus setelah plywood digunakan } \\
\text { beberapa kali } \\
\text { Biaya total yang dikeluarkan lebih mahal } \\
\text { dibandingkan bekisting aluminium dan baja } \\
\text { apabila digunakan pada proyek berskala besar }\end{array}$ \\
\hline
\end{tabular}


Tabel 3. Keuntungan dan Kerugian Bekisting Aluminium

\begin{tabular}{ll}
\hline Keuntungan & Kerugian \\
\hline $\begin{array}{l}\text { Dapat digunakan terus menerus } \\
\text { Material ringan }\end{array}$ & $\begin{array}{l}\text { Biaya yang dikeluarkan di awal tinggi } \\
\text { Fleksibilitas rendah } \\
\text { Biaya total yang dikeluarkan lebih tinggi } \\
\text { dibandingkan bekisting plywood dilapisi film, } \\
\text { apabila digunakan pada proyek berskala kecil }\end{array}$ \\
$\begin{array}{l}\text { Memberikan hasil cetakan permukaan kolom } \\
\text { yang halus }\end{array}$ & \\
$\begin{array}{l}\text { Durabilitas material tinggi } \\
\text { Ramah lingkungan (tidak menghasilkan }\end{array}$ & \\
$\begin{array}{l}\text { Biaya total yang dikeluarkan lebih rendah } \\
\text { dibandingkan bekisting plywood dilapisi film, } \\
\text { apabila digunakan pada proyek berskala besar }\end{array}$ & \\
\hline
\end{tabular}

Tabel 4. Keuntungan dan Kerugian Bekisting Baja

\begin{tabular}{ll}
\hline Keuntungan & Kerugian \\
\hline $\begin{array}{l}\text { Dapat digunakan terus menerus } \\
\text { Memberikan hasil cetakan permukaan kolom } \\
\text { yang halus }\end{array}$ & $\begin{array}{l}\text { Biaya yang dikeluarkan di awal tinggi } \\
\text { Fleksibilitas rendah }\end{array}$ \\
$\begin{array}{l}\text { Durabilitas material tinggi } \\
\text { Biaya total yang dikeluarkan lebih tinggi } \\
\text { dibandingkan bekisting } \text { plywood dilapisi film, } \\
\text { apabila digunakan pada proyek berskala kecil }\end{array}$ \\
$\begin{array}{l}\text { Ramah lingkungan (tidak menghasilkan } \\
\text { limbah) }\end{array}$ & Material Berat \\
$\begin{array}{l}\text { Biaya total yang dikeluarkan lebih rendah } \\
\text { dibandingkan bekisting plywood dilapisi film, } \\
\text { apabila digunakan pada proyek berskala besar }\end{array}$ & \\
\hline
\end{tabular}

\section{Teknik Pemeringkatan}

Berikut ini adalah hasil pengumpulan data berupa skor untuk setiap alternatif bekisting kolom berdasarkan kriteria yang telah ditentukan, yang diperoleh dari pengisian kuesioner oleh narasumber (Tabel 5 hingga Tabel 7)

Tabel 5. Hasil Analisis Teknik Pemeringkatan Bekisting Plywood Dilapisi Film

\begin{tabular}{cc}
\hline \multicolumn{2}{c}{ Plywood Dilapisi Film } \\
\hline Kriteria & Skor \\
& \\
\hline A. Kemudahan Pengerjaan & 3.64 \\
B. Waktu Pengerjaan & 3.64 \\
C. Biaya & 3.73 \\
D. Mutu/Hasil Cetakan Beton & 3.09 \\
E. Ketersediaan Material & 3.82 \\
F. Durabilitas & 2.55 \\
\hline Rata-Rata & 3.41 \\
\hline
\end{tabular}


Tabel 6. Hasil Analisis Teknik Pemeringkatan Bekisting Aluminium

\begin{tabular}{lc}
\hline \multicolumn{1}{c}{ Aluminium } \\
\hline \multicolumn{1}{c}{ Kriteria } & Skor \\
& \\
\hline A. Kemudahan Pengerjaan & 3.55 \\
B. Waktu Pengerjaan & 3.73 \\
C. Biaya & 2.64 \\
D. Mutu/Hasil Cetakan Beton & 4.36 \\
E. Ketersediaan Material & 3.36 \\
F. Durabilitas & 4.18 \\
\hline & 3.64 \\
\hline
\end{tabular}

Tabel 7. Hasil Analisis Teknik Pemeringkatan Bekisting Baja

\begin{tabular}{|c|c|}
\hline \multicolumn{2}{|l|}{ Baja } \\
\hline Kriteria & Skor \\
\hline A. Kemudahan Pengerjaan & 3.27 \\
\hline B. Waktu Pengerjaan & 3.36 \\
\hline C. Biaya & 2.73 \\
\hline D. Mutu/Hasil Cetakan Beton & 4.00 \\
\hline E. Ketersediaan Material & 3.18 \\
\hline F. Durabilitas & 4.09 \\
\hline Rata-Rata & 3.44 \\
\hline
\end{tabular}

3. Matriks Perbandingan Berpasangan

Pada tahap ini dilakukan perhitungan skor untuk masing-masing kriteria. Setelah diperoleh nilai untuk masingmasing kriteria, maka setiap kriteria diberikan peringkat berdasarkan nilai nya masing-masing, seperti yang dapat di lihat pada tabel berikut (Tabel 8).

Tabel 8. Hasil Analisis Matriks Perbandingan Berpasangan

\begin{tabular}{cccc}
\hline & Kriteria & Skor & Peringkat \\
\hline A & Kemudahan Pengerjaan & 4.64 & 3 \\
B & Waktu Pengerjaan & 3.36 & 6 \\
C & Biaya & 4.09 & 5 \\
D & Mutu/Hasil Cetakan Beton & 8.09 & 1 \\
E & Ketersediaan Material & 4.27 & 4 \\
F & Durabilitas & 6.55 & 2 \\
\hline
\end{tabular}

\section{Matriks Keputusan}

Pada bagian ini dilakukan analisis matriks keputusan (Tabel 9) yang memberikan skor akhir untuk masing-masing alternatif bekisting. Angka-angka yang terdapat pada bagian bobot, merupakan skor masing-masing alternatif yang diperoleh dari matriks perbandingan berpasangan. Sedangkan untuk angka-angka yang terletak di samping tulisan masing-masing alternatif, terbagi menjadi dua, bagian atas dan bawah. Angka pada bagian atas merupakan skor 
untuk masing-masing alternatif yang diperoleh dari teknik pemeringkatan, dan angka pada bagian bawah merupakan hasil perkalian antara angka yang terletak pada bagian atas dengan bobot masing-masing kriteria, kemudian angka-angka ini dijumlahkan untuk memperoleh skor akhir.

\begin{tabular}{|c|c|c|c|c|c|c|c|}
\hline \multicolumn{8}{|c|}{ Tabel 9. Matriks Keputusan } \\
\hline & \multicolumn{6}{|c|}{ Kriteria } & \multirow{4}{*}{$\begin{array}{l}\text { Skor } \\
\text { Akhir }\end{array}$} \\
\hline & A & $\mathrm{B}$ & $\mathrm{C}$ & $\mathrm{D}$ & $\mathrm{E}$ & $\mathrm{F}$ & \\
\hline & \multicolumn{6}{|c|}{ Bobot } & \\
\hline Alternatif & 4.64 & 3.36 & 4.09 & 8.09 & 4.27 & 6.55 & \\
\hline $\begin{array}{l}\text { Plywood } \\
\text { Dilapisi } \\
\text { Film }\end{array}$ & $\begin{array}{c}3.64 \\
16.86\end{array}$ & $\begin{array}{c}3.64 \\
12.23\end{array}$ & $\begin{array}{c}3.73 \\
15.25\end{array}$ & $\begin{array}{c}3.09 \\
25.01\end{array}$ & $\begin{array}{r}3.82 \\
16.31\end{array}$ & $\begin{array}{c}2.55 \\
16.66\end{array}$ & 102.32 \\
\hline Aluminium & $\begin{array}{c}3.55 \\
16.44\end{array}$ & $\begin{array}{c}3.73 \\
12.54\end{array}$ & $\begin{array}{c}2.64 \\
10.79\end{array}$ & $\begin{array}{c}4.36 \\
35.31\end{array}$ & $\begin{array}{r}3.36 \\
14.37\end{array}$ & $\begin{array}{c}4.18 \\
27.37\end{array}$ & 116.81 \\
\hline Baja & $\begin{array}{c}3.27 \\
15.17\end{array}$ & $\begin{array}{c}3.36 \\
11.31\end{array}$ & $\begin{array}{c}2.73 \\
11.16\end{array}$ & $\begin{array}{c}4.00 \\
32.36\end{array}$ & $\begin{array}{c}3.18 \\
13.60\end{array}$ & $\begin{array}{c}4.09 \\
26.78\end{array}$ & 110.38 \\
\hline
\end{tabular}

\section{Tahap Pengembangan}

Berikut ini adalah hasil perhitungan biaya untuk masing-masing alternatif yang ditampilkan pada Tabel 10 hingga Tabel 12.

Tabel 10. Perhitungan Biaya Bekisting Plywood Dilapisi Film

\begin{tabular}{|c|c|c|c|}
\hline Material dan Aksesoris & Biaya per $\mathrm{m}^{2}$ & Luas $\left(\mathrm{m}^{2}\right)$ & Biaya Total \\
\hline $\begin{array}{l}\text { Plywood dilapisi film } \\
\text { tebal } 18 \mathrm{~mm}\end{array}$ & \multirow{6}{*}{ Rp700,000 } & \multirow{6}{*}{278.88} & \multirow{6}{*}{ Rp195,216,000 } \\
\hline Balok Kayu H20 & & & \\
\hline $\begin{array}{l}\text { Waller Beam } \\
\text { Tie Rod }\end{array}$ & & & \\
\hline Wing Nut & & & \\
\hline Swivel Base Double & & & \\
\hline Support Pipe & & & \\
\hline \multirow[t]{2}{*}{$\begin{array}{l}\text { Plywood dilapisi film } \\
\text { tebal } 18 \mathrm{~mm} \text { (tambahan) }\end{array}$} & Rp152,000 & 557.76 & Rp84,779,520 \\
\hline & & Jumlah & Rp279,995,520 \\
\hline
\end{tabular}


Tabel 11. Perhitungan Biaya Bekisting Aluminium

\begin{tabular}{lccc}
\hline Material dan Aksesoris & Biaya per $\mathrm{m}^{2}$ & Luas $\left(\mathrm{m}^{2}\right)$ & Biaya Total \\
\hline Panel Aluminium & & & \\
Wedge and Pin & & \\
Waller Beam & & \\
Tie Rod & Rp1,960,000 & 278.88 & Rp546,604,800 \\
Wing Nut & & \\
Swivel Base Double & & \\
Support Pipe & & \\
\hline
\end{tabular}

Tabel 12. Perhitungan Biaya Bekisting Baja

\begin{tabular}{lccc}
\hline Material dan Aksesoris & Biaya per $\mathrm{m}^{2}$ & Luas $\left(\mathrm{m}^{2}\right)$ & Biaya Total \\
\hline Panel Baja & & & \\
Waller Beam & & & \\
Tie Rod & Rp1,680,000 & 278.88 & Rp468,518,400 \\
Wing Nut & & & \\
Swivel Base Double & & \\
Support Pipe & & \\
\hline
\end{tabular}

\section{Tahap Rekomendasi}

Berdasarkan hasil pengumpulan dan pengolahan data yang telah dilakukan pada tahap analisis, dapat dilihat bahwa jenis bekisting kolom yang memiliki nilai tertinggi adalah bekisting kolom dengan menggunakan aluminium. Oleh karena itu, bekisting kolom dengan menggunakan aluminium menjadi alternatif yang disarankan untuk digunakan pada konstruksi gedung bertingkat.

\section{Hasil Analisis dan Pembahasan}

1. Hasil Analisis Teknik Pemeringkatan

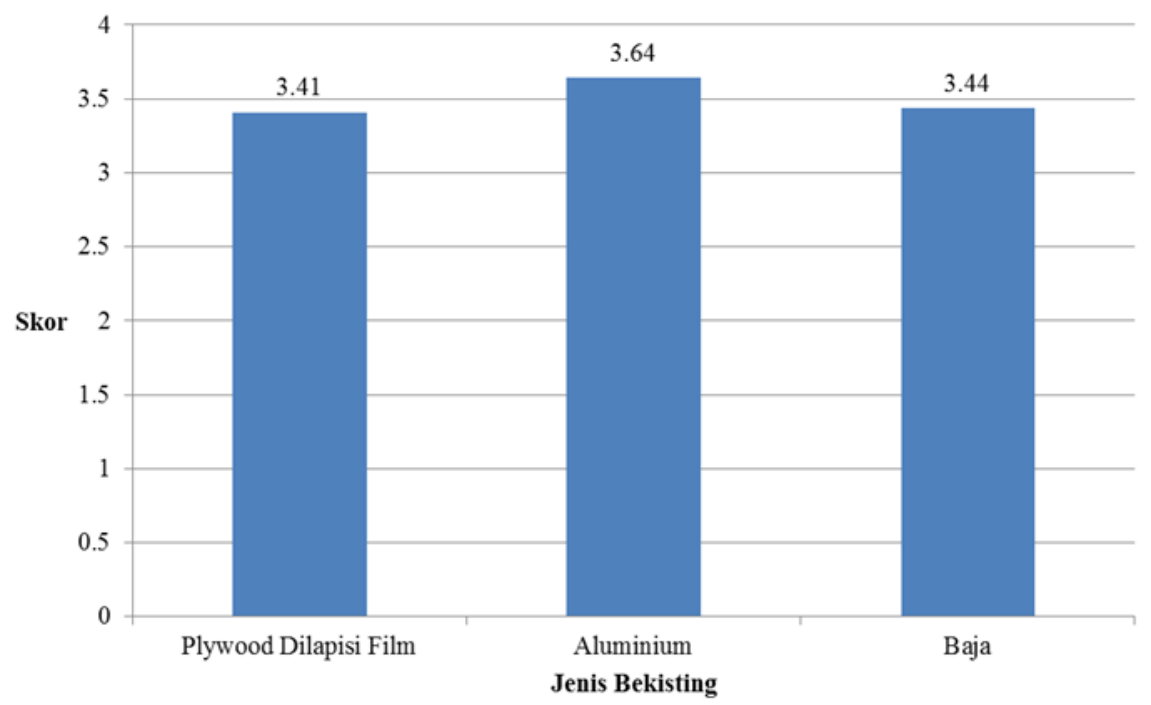

Gambar 2. Grafik Hasil Analisis Teknik Pemeringkatan

Berdasarkan hasil analisis teknik pemeringkatan yang telah dituangkan dalam bentuk grafik pada halaman sebelumnya, dapat dilihat bahwa alternatif yang memiliki skor tertinggi adalah aluminium dengan skor 3.64, diikuti baja dengan skor 3.44, dan plywood dilapisi film dengan skor 3.41. Namun, dikarenakan selisih skor antar 
ketiga alternatif tersebut tidak terlalu besar, maka ketiga alternatif tersebut kembali dianalisis pada tahapan matriks keputusan.

2. Hasil Analisis Matriks Perbandingan Berpasangan

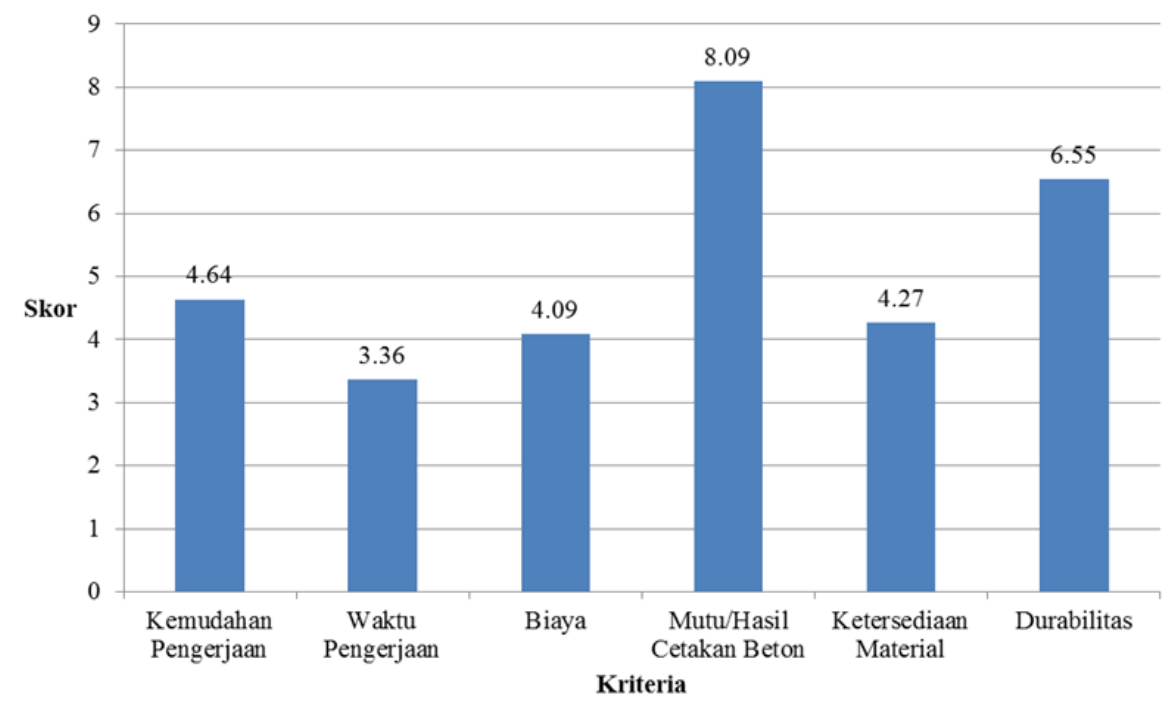

Gambar 3. Grafik Hasil Analisis Matriks Perbandingan Berpasangan

Berdasarkan hasil analisis matriks perbandingan berpasangan yang telah dituangkan dalam bentuk grafik di atas, dapat dilihat bahwa kriteria mutu/hasil cetakan beton menjadi kriteria dengan skor tertinggi yaitu 8.09, diikuti oleh durabilitas dengan skor 6.55, kemudahan pengerjaan dengan skor 4.64, ketersediaan material dengan skor 4.27, biaya dengan skor 4.09, dan terakhir waktu pengerjaan dengan skor 3.36. Dari hasil analisis ini dapat disimpulkan bahwa kriteria yang paling berpengaruh terhadap pekerjaan bekisting kolom adalah kriteria mutu/hasil cetakan beton, dikarenakan kriteria tersebut memperoleh skor tertinggi.

3. Hasil Analisis Matriks Keputusan

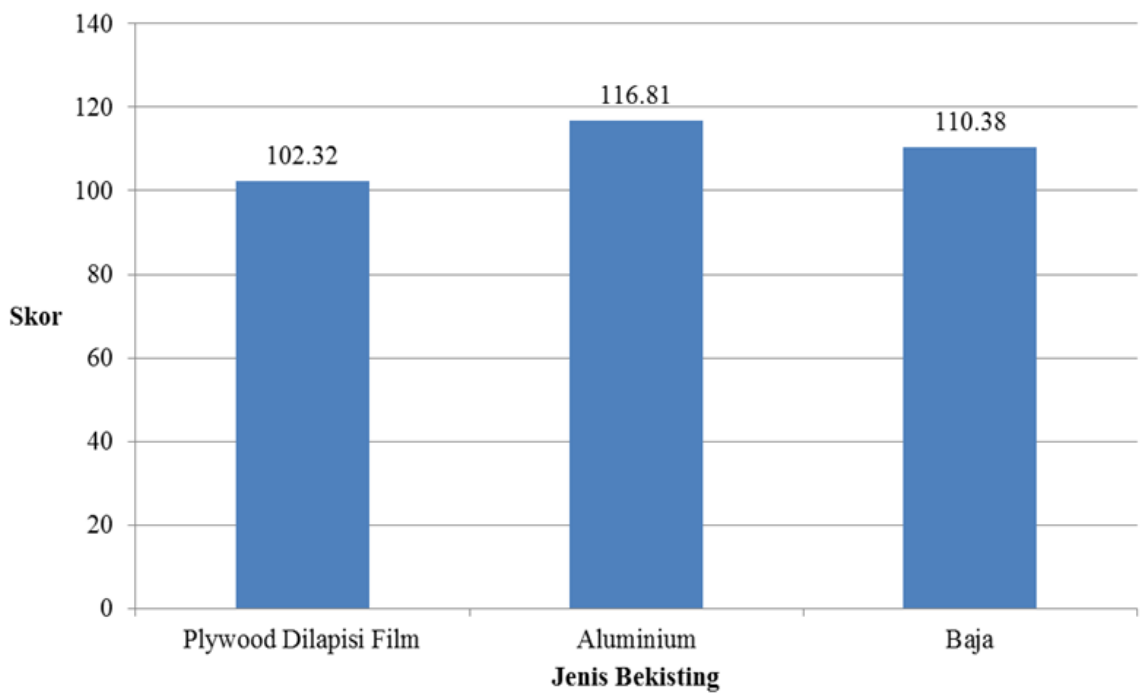

Gambar 4. Grafik Hasil Analisis Matriks Keputusan

Berdasarkan hasil analisis matriks keputusan yang telah dituangkan dalam bentuk grafik pada halaman sebelumnya, dapat dilihat bahwa alternatif yang memiliki skor akhir tertinggi adalah aluminium dengan skor 116.81, diikuti baja dengan skor 110.38, dan plywood dilapisi film dengan skor 102.32. Maka, dapat disimpulkan bahwa alternatif jenis bekisting terbaik yang dapat digunakan untuk bekisting kolom beton gedung bertingkat adalah bekisting aluminium yang memperoleh skor akhir tertinggi.

4. Hasil Analisis Biaya 


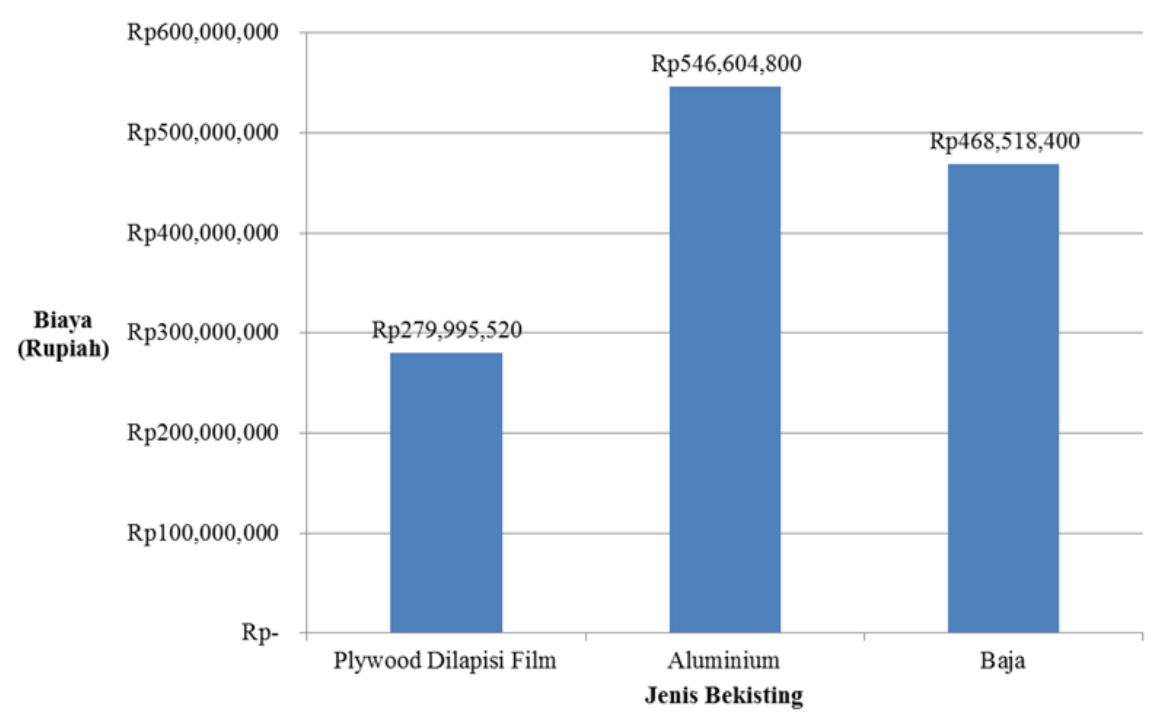

Gambar 5. Grafik Hasil Analisis Biaya

Berdasarkan hasil analisis matriks biaya yang telah dituangkan dalam bentuk grafik di atas, dapat dilihat bahwa alternatif yang memiliki skor biaya tertinggi adalah aluminium dengan total biaya sebesar Rp 546.604.800, diikuti baja dengan total biaya sebesar Rp 429.475.20, dan plywood dilapisi film dengan total biaya sebesar $\mathrm{Rp}$ 279.995.520. Maka, dapat disimpulkan bahwa alternatif jenis bekisting yang memiliki biaya terbesar adalah aluminium, sedangkan alternatif yang memiliki biaya terendah adalah plywood dilapisi film.

\section{KESIMPULAN DAN SARAN}

\section{Kesimpulan}

Berdasarkan hasil analisis yang telah dilakukan dalam penelitian ini, maka dapat disimpulkan bahwa:

1. Jenis bekisting terbaik yang dapat digunakan pada konstruksi kolom gedung bertingkat adalah bekisting yang menggunakan material aluminium, dimana alternatif bekisting aluminium ini menjadi alternatif yang mendapatkan skor tertinggi setelah dilakukan analisis matriks keputusan (decision matrix).

2. Kriteria yang paling berpengaruh terhadap pekerjaan bekisting kolom gedung bertingkat adalah mutu/hasil cetakan beton, dimana kriteria ini menjadi kriteria yang mendapatkan skor tertinggi setelah dilakukan analisis matriks perbandingan berpasangan (paired comparison matrix).

\section{Saran}

Berdasarkan hasil analisis yang telah dilakukan dalam penelitian ini, penulis memberikan beberapa saran sebagai berikut:

1. Jenis bekisting aluminium menjadi jenis bekisting kolom yang penulis sarankan untuk digunakan pada konstruksi gedung bertingkat, terutama pada proyek-proyek gedung yang memiliki volume pekerjaan kolom yang besar. Hal ini dikarenakan meskipun biaya yang diperlukan cukup besar, bekisting aluminium dapat digunakan terus menerus hingga selesainya proyek.

2. Untuk penelitian selanjutnya, disarankan untuk memperluas penelitian dengan menganalisis jenis-jenis bekisting untuk struktur lain selain kolom, dengan menggunakan metode value engineering.

\section{DAFTAR PUSTAKA}

Fisk, Edward R. Contractor's Project Guide to Public Agency Contracts. New Jersey: Wiley, 1982.

Hanna, Awad S. Concrete Formwork Systems. New York: Marcel Dekker Inc, 1998.

Nugroho, Sony Prakoso. Analisis Perbandingan Biaya Bekisting Antara Beksiting Multiplek dan Bekisting Tegofilm Untuk Kolom Gedung Bertingkat. Yogyakarta: Universitas Islam Indonesia, 2018. 
Penerapan Value Engineering dalam Pemilihan Jenis

Bekisting Kolom Beton pada Konstruksi Gedung Bertingkat

Pratama, H.S., Anggraeni, R.K., Hidayat, A., dan Khasani, R.R. Analisa Perbandingan Penggunaan Bekisting Konvensional, Semi Sistem, dan Sistem (PERI) Pada Kolom Gedung Bertingkat. Semarang: Universitas Diponegoro, 2017.

SAVE International. About Value Engineering. https://www.value-eng.org/page/AboutVE. (diakses 9 Agustus 2019). 